\title{
Maternal Pre-Pregnancy Cardiovascular Risk Factors and Offspring and Grandoffspring Health: Bogalusa Daughters
}

\author{
Emily W. Harville ${ }^{1, * \mathbb{D}}$, John W. Apolzan ${ }^{2} \mathbb{D}$ and Lydia A. Bazzano ${ }^{1}$ \\ 1 Department of Epidemiology, Tulane University School of Public Health and Tropical Medicine, \\ New Orleans, LA 70112, USA; lbazzano@tulane.edu \\ 2 Pennington Biomedical Research Center, Louisiana State University System, Baton Rouge, LA 70808, USA; \\ john.apolzan@pbrc.edu \\ * Correspondence: eharvill@tulane.edu; Tel.: +1-504-988-7327
}

Received: 14 November 2018; Accepted: 19 December 2018; Published: 21 December 2018

\begin{abstract}
Both maternal pre-pregnancy body mass index (BMI) and gestational weight gain have been associated with cardiovascular health in the offspring beyond two generations. A total of 274 daughters (aged 12-54) of 208 mothers who participated in the Bogalusa Heart Study were interviewed about their reproductive history. Mothers' data was taken from the original study, and cardiovascular measures at the visit prior to pregnancy were correlated with daughter's measures. Maternal pre-pregnancy BMI, skinfold, and waist circumference were examined as a predictor of daughters' blood pressure, lipids, and glucose, as well as a predictor of birthweight and gestational age of grandchildren. Maternal pre-pregnancy BMI was associated with higher blood pressure and lower low-density lipoprotein (LDL) and cholesterol in the daughters. Most maternal cardiometabolic risk factors were not associated with grandchildren's birth outcomes, even though higher cholesterol and LDL was associated with lower gestational age, and higher BMI and skinfold thickness with an increased risk of preterm birth. In this pilot study, some associations were found between maternal adiposity and cardiovascular risk, daughters' cardiovascular risk, and grandchild birth outcomes. Lack of conclusive associations could be due to a true lack of effect, effects being primarily mediated through daughter's BMI, or the low power of the study.
\end{abstract}

Keywords: body mass index; skinfold thickness; lipids; blood; birth weight; gestational age; transgenerational

\section{Introduction}

The fact that the groups that have experienced the most oppression and discrimination across generations often have the worst health outcomes, and racial disparities persist across populations with comparable access to health care and, in otherwise low-risk groups [1-4], suggests that health is affected by factors beyond an individual's immediate circumstances. The developmental origin of health and disease theory indicates that adult health can be programmed by in utero exposures [5].

Both maternal pre-pregnancy body mass index (BMI) and gestational weight gain have been associated with cardiovascular health in the offspring. High pre-pregnancy BMI predicts adiposity, insulin resistance, lipids, and blood pressure in childhood [6-8]. The Jerusalem Perinatal Study also found that greater maternal pre-pregnancy BMI, independent of gestational weight gain and confounders, was significantly associated with higher adult offspring BMI, waist circumference, systolic and diastolic blood pressure (SBP and DBP), insulin, and triglycerides [9]. However, these studies generally find that the majority of the effect is due to offspring BMI $[8,9]$. Therefore, it may 
ultimately not prove much beyond the fact that obesity runs in families, which is a fact well-known to be due to both genetic and environmental factors [10]. However, few studies have examined other indicators of maternal adiposity, such as weight circumference.

Some recent work has been extended beyond two generations. In the Panel Study of Income Dynamics, grandparental obesity was found to be associated with grandchildren's obesity, independent of parental BMI [11]. Prenatal exposure to famine was associated with hyperglycemia in generations 2 and 3 in a Chinese study [12]. The Overkalix (Sweden) study of historical harvest records [13] for 317 people found that, if the paternal grandmother experienced changes in food supply year to year in early life, the granddaughter had increased risk of cardiovascular mortality. Such associations were not found with the experience of the maternal grandmother or either maternal or paternal grandfather.

The mirroring of disparities in birth outcomes and cardiometabolic health [14-16] also suggests that it is worthwhile to examine the interrelationship between cardiovascular and reproductive health. A higher incidence of cardiovascular mortality was associated with lower grandchild birthweight in a very large study in Norway [17]. For diabetes mortality, U-shaped associations with maternal grandmother's diabetes mortality risk were seen for grandchild birthweight, while, for all other grandparents, higher diabetes mortality was associated with lower birthweight [17]. However, a study in Maltese women [18] found that, while generation 1 BMI was directly linked to generation 2 birthweight and BMI, there was no association with generation 3 birthweight. Metabolic syndrome in the generation 1 also did not produce any changes in the birthweight of generation 2 or 3. Our previous analysis in the existing Bogalusa Heart Study (BHS) data [19] found that pre-pregnancy cardiometabolic risk factors (BMI, triglycerides, low-density lipoprotein (LDL), glucose) were associated with birthweight and gestational age in generation 3.

Because of the difficulty of performing multigenerational prospective studies, many previous studies are Scandinavian and take advantage of those countries' ability to link across databases but provide limited racial and socioeconomic diversity. Our previous BHS analysis did not purposefully recruit second and third generation participants, relying instead on a retrospective linkage. In this study, we intentionally recruited the daughters of former BHS participants, with the goal both of testing feasibility for this type of study design, and examining maternal pre-pregnancy cardiovascular health and daughters' cardiometabolic risk factors, and grandchild birth outcomes, in the second and third generations of the Bogalusa Heart Study. We hypothesized that women with worse cardiovascular health prior to pregnancy would have daughters with cardiovascular health, and grandchildren with lower birthweight and gestational age, even controlling for generation 2 BMI.

\section{Materials and Methods}

This study included 274 daughters of 208 female Bogalusa Heart Study participants. The Bogalusa Heart Study (BHS) is a series of studies of cardiovascular health in a semirural, biracial population (65\% white and 35\% black), founded by Dr. Gerald Berenson in 1973, which generated some of the seminal literature relating childhood risk factors to adult cardiometabolic health [20,21]. Furthermore, 1803 women participated in the Bogalusa Babies study, which was a study of reproductive health and pregnancy outcomes nested in BHS. Women were interviewed by phone or in the clinic about their pregnancy history. They had an estimated 1653 daughters in the relevant age range (12+). The Bogalusa Daughters project gathered data on female offspring ages 12 and older of participants in the Bogalusa Babies study. (Age 12 was chosen as the average age of menarche for girls as well as an age when participants were likely to be able to understand the study topic and thus give informed assent). Compared with the overall parous Babies study population, the included group was more likely to be black, more likely to have smoked, and had less education [22] (Harville et al., under review). This study was approved by the Institutional Review Board of Tulane University (\#862715).

Mothers' data was taken from the original study, and cardiovascular measures at the visit prior to pregnancy were identified. For the daughters, study procedure varied slightly depending on the age and geographic location of the participants. Bogalusa Babies participants (mothers) were contacted 
by mail and phone, and contact information for their daughters was obtained. The daughter was then contacted by telephone. Socio-demographics were updated. If she was able to attend a clinic visit, then blood pressure, height, and weight were measured and a fasting blood draw was taken (details of measures below). An interview was conducted about her reproductive history, and medical records were requested about her pregnancies. If the daughter was aged 12-17, a modified version of this protocol was implemented, with fewer questions about pregnancy. Daughters who lived too far away to visit the clinic, or who did not wish to, were interviewed by telephone. If they were willing to provide biological measures but did not live near Bogalusa, they were invited to visit a local LabCorp for lipid and glucose measurements.

\subsection{Cardiovascular Measures}

Measures were taken with a similar protocol in both generations even though, in a few cases, the protocol in early years (mothers) was different than that for the daughters' follow-up. Anthropometric measurements were conducted on individuals in light clothing without shoes using a standard protocol. Determinations of height (to nearest $0.1 \mathrm{~cm}$ ) and weight (to nearest $0.1 \mathrm{~kg}$ ) were performed in duplicate. Triceps and subscapular skinfold thickness and waist and hip circumferences were measured in triplicate (mothers only, waist circumference was not measured in early years of BHS). For mothers, blood pressure was measured in duplicate by trained research technicians. For daughters, blood pressure was measured using the HEM 907 ZL Non-Invasive Blood Pressure Monitor by Omron HealthCare CO, LTD, Kyoto, Japan. This instrument provides BP and heart rate, and a total of four readings are taken and are averaged for analysis. Plasma glucose was measured using the hexokinase method. Serum total cholesterol and triglycerides were measured by enzymatic procedures. LDL cholesterol was estimated by using the Friedwald equation.

\subsection{Reproductive Measures}

Adult women were interviewed about their age at menarche, gravidity, parity, fertility issues, birthweight, and gestational age of their children using a standardized form. These questions have been used in the Bogalusa Babies study and self-report for pregnancy history is generally reliable [23-25]. Adolescents $(<18)$ were asked about age at menarche and any children they had. If they reported having children, information about those pregnancies was gathered. Low birthweight (LBW) was defined as birthweight $<2500 \mathrm{~g}$, and preterm birth (PTB) was defined as birth three or more weeks early. If a woman said that her child had been born on time but did not specify further, gestational age at birth was imputed as 40 weeks.

\subsection{Analysis}

Descriptive data were calculated using frequency tabulations and measures of central tendency and variability. Racial differences in cardiovascular and reproductive outcomes were examined by using t-tests for continuous measures and chi-square tests for categorical variables. Cardiovascular measures were compared across generations. If the mother had more than one BHS visit, the study visit that occurred prior to the pregnancy with the daughter was determined. Given the study design, this did not occur at a standardized time before pregnancy. Median time between this visit and daughter's birth was four years. Cardiovascular measures at the visit prior to pregnancy were compared to the daughter's measures by examining correlations between daughter's risk factors and her mother's pre-pregnancy and mean adult measures.

Cardiometabolic predictors were standardized, so that all effect estimates are presented for a 1-SD increase. Maternal pre-pregnancy adiposity, as indicated by BMI, skinfold, and waist circumference at the study visit prior to pregnancy, was examined as a predictor of daughters' cardiovascular risk. Maternal pregnancy weight gain during the pregnancy with the daughter was also examined as a predictor of daughters' cardiometabolic risk. Generalized estimating equations (linear models), with control for mother's age, daughter's age, daughter's BMI, and race were used to predict daughters' 
cardiovascular risk factors with control for clustering within family. For other measures of adiposity, a final model also controlled for maternal BMI. Missing data were not extensive (see Table 1), but multiple imputation (proc mi and mianalyze) were used to control for missing data on confounders. All models with 200 or more observations were examined for interaction with race, using interaction terms and stratification.

Maternal pre-pregnancy cardiovascular risk was also examined as a predictor of the birthweight and gestational age of the first grandchild as well any LBW or PTB across all pregnancies. Again, generalized estimating equations (linear and logistic models) with control for maternal and daughter's age and daughter's BMI were used to control for clustering within family.

\section{Results}

Fifty-five percent of participants were black and $45 \%$ were white (Table 1), and slightly more than half had at least one pregnancy. Daughters were on average 27 years old at the time of the interview, with a range of $12-54$ years old, and mean age during the first pregnancy was 20.6 years. Black women had a higher mean age at interview (28.1 vs. $25.8, p=0.02)$, a lower mean age at first pregnancy $(19.7$ vs. 22.5, $p<0.01)$, a higher mean BMI (33.3 vs. $29.9, p<0.01)$, a higher mean blood pressure $(p<0.05$, data not shown), a lower mean and median triglycerides $(p<0.01)$, and lower birthweight at first pregnancy (3081 vs. $3289 \mathrm{~g}, p=0.03$ ). There were no racial differences in LDL, high-density lipoprotein (HDL), or glucose (data not shown).

Mothers' and daughters' risk factors were correlated at between 0.2 and 0.3 . When limited to measures taken prior to pregnancy on mothers, correlations were not as strong (Table 2).

Maternal pre-pregnancy BMI was associated with higher blood pressure, lower LDL, and lower total cholesterol levels in the daughters (Table 3). Maternal subscapular skinfold was associated with higher diastolic blood pressure, but this result disappeared when BMI was adjusted for, while total cholesterol was higher only after BMI was adjusted for. Waist circumference was associated with lower LDL and total cholesterol, but those associations disappeared after BMI was adjusted for. Similarly, the association between higher gestational weight gain and higher triglycerides disappeared after adjustment for confounders. No interactions with race were statistically significant, but the association between maternal BMI and blood pressure appeared to be stronger in black women (adjusted beta for SBP in black women 3.16, Standard Error (SE(b)) 1.21, $p=0.01$, for white women, $-0.54(0.92), p=0.55$, for DBP, 2.27 (1.05), $p=0.03,0.54$ (0.93), 0.56). The association between maternal BMI and HDL was stronger for white women (adjusted beta in white women 7.41 (1.55), $p<0.01$, for black women, -0.81 $(1.48), p=0.58)$. The association between pregnancy weight gain and triglycerides appeared stronger in black women (adjusted beta $7.03(4.15), p=0.09)$ than in white women $(-5.11(4.48), p=0.25)$.

Maternal cardiometabolic risk factors were associated with birth outcomes in grandchildren only to a limited extent (Table 4). DBP was associated with a higher risk of a LBW baby (attenuated after adjustment for confounders). Higher cholesterol and LDL was associated with lower gestational age, and higher BMI and skinfold with an increased risk of PTB. There was also a tendency for triglycerides to be associated with lower birthweight. 
Table 1. Descriptive data, pilot study of daughters of Bogalusa Heart Study participants

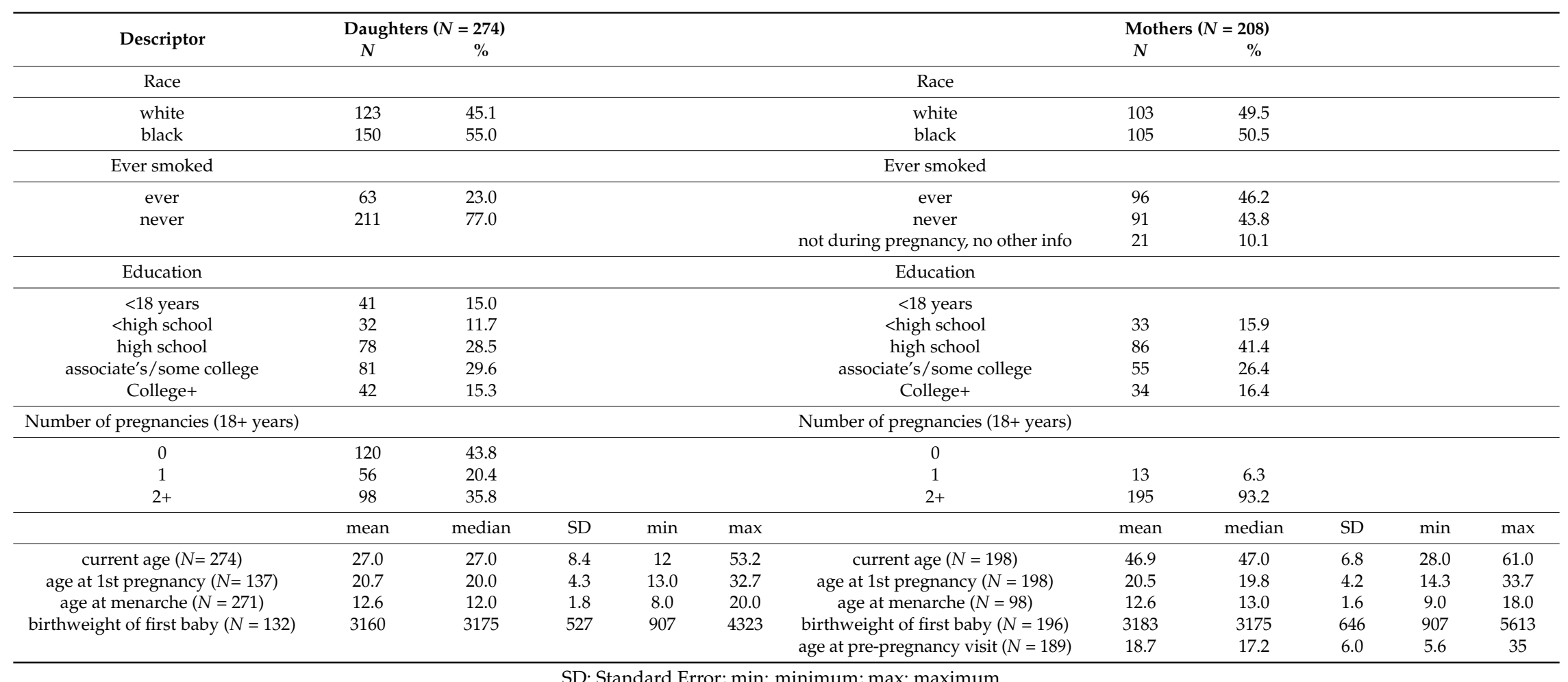

SD: Standard Error; min: minimum; max: maximum. 
Table 2. Adiposity and cardiometabolic health across generations. The Bogalusa Daughters study.

\begin{tabular}{|c|c|c|c|c|c|c|c|c|c|c|c|c|}
\hline \multirow[t]{3}{*}{ Cardiovascular Risk Factor } & \multicolumn{6}{|c|}{ Daughters $(n=222)$} & \multicolumn{6}{|c|}{ Mothers $(n=198)$} \\
\hline & \multirow[b]{2}{*}{ mean } & \multirow[b]{2}{*}{ median } & \multirow[b]{2}{*}{ SD } & \multirow[b]{2}{*}{$\min$} & \multirow[b]{2}{*}{$\max$} & & \multicolumn{6}{|c|}{ pre-pregnancy } \\
\hline & & & & & & & mean & median & SD & $\min$ & $\max$ & $\begin{array}{c}\mathrm{r} *(n= \\
161)\end{array}$ \\
\hline BMI * & 31.7 & 30.4 & 9.1 & 14.1 & 71.1 & & 23 & 21.3 & 5.6 & 13.4 & 49.2 & 0.11 \\
\hline systolic blood pressure (mmHg) & 118.3 & 116 & 13.3 & 84 & 175 & & 107 & 107 & 9.4 & 83.3 & 145 & 0.11 \\
\hline diastolic blood pressure $(\mathrm{mmHg})$ & 75.3 & 75 & 11 & 51 & 112 & & 68.1 & 68 & 7.4 & 45.7 & 87.3 & 0.04 \\
\hline $\operatorname{HDL}(\mathrm{mg} / \mathrm{dL})$ & 51.6 & 49.5 & 13.8 & 21 & 99 & & 168.5 & 167.5 & 30.6 & 100 & 295 & 0.01 \\
\hline LDL (mg/dL) & 99.9 & 97 & 29.4 & 37 & 228 & & 57.3 & 56 & 16.9 & 4.4 & 108.6 & 0.07 \\
\hline total cholesterol $(\mathrm{mg} / \mathrm{dL})$ & 170.1 & 168 & 34.7 & 18 & 289 & & 100.1 & 97.3 & 27.2 & 51.3 & 192.8 & 0.18 \\
\hline triglycerides $(\mathrm{mg} / \mathrm{dL})$ & 93.2 & 77 & 50.3 & 30 & 376 & & 78.6 & 68 & 45.4 & 23 & 417 & 0.25 \\
\hline \multirow[t]{4}{*}{ glucose $(\mathrm{mg} / \mathrm{dL})$} & 97.5 & 93 & 26.6 & 66 & 323 & & 81.5 & 80 & 8.4 & 62 & 107 & 0.21 \\
\hline & \multicolumn{6}{|c|}{ mothers } & & & & & & \\
\hline & \multicolumn{6}{|c|}{ adult } & & & & & & \\
\hline & mean & median & $\mathrm{SD}$ & $\min$ & $\max$ & $\mathrm{r}(n=170)$ & & & & & & \\
\hline BMI * & 28 & 26.2 & 6.7 & 17.9 & 46.8 & 0.37 & & & & & & \\
\hline systolic blood pressure (mmHg) & 110.9 & 109.7 & 10.1 & 92.7 & 147.1 & 0.17 & & & & & & \\
\hline diastolic blood pressure $(\mathrm{mmHg})$ & 73.6 & 72.9 & 6.8 & 56.3 & 96.9 & 0.23 & & & & & & \\
\hline $\mathrm{HDL}(\mathrm{mg} / \mathrm{dL})$ & 52.9 & 53 & 11.4 & 29 & 99 & 0.31 & & & & & & \\
\hline LDL (mg/dL) & 114.1 & 14.8 & 25.3 & 60.9 & 187.8 & 0.37 & & & & & & \\
\hline total cholesterol $(\mathrm{mg} / \mathrm{dL})$ & 181.3 & 182.4 & 27.8 & 126.5 & 260 & 0.36 & & & & & & \\
\hline triglycerides $(\mathrm{mg} / \mathrm{dL})$ & 97.6 & 89 & 55.6 & 33 & 548.3 & 0.33 & & & & & & \\
\hline glucose (mg/dL) & 84.7 & 82 & 13.6 & 65 & 171.3 & 0.19 & & & & & & \\
\hline
\end{tabular}


Table 3. Maternal adiposity as a predictor of child cardiovascular risk, the Bogalusa Daughters Study.

\begin{tabular}{|c|c|c|c|c|c|c|c|c|c|c|c|c|c|c|c|c|c|c|}
\hline \multirow[t]{3}{*}{ Risk Factor } & \multicolumn{6}{|c|}{ BMI $(n=200)$} & & & & \multicolumn{9}{|c|}{ Subscapular Skinfold $(n=200)$} \\
\hline & \multicolumn{3}{|c|}{ Unadjusted } & \multicolumn{3}{|c|}{ Adjusted * } & & & & \multicolumn{3}{|c|}{ Unadjusted } & \multicolumn{3}{|c|}{ Adjusted * } & \multicolumn{3}{|c|}{ Adjusted + BMI } \\
\hline & beta & SE & $p$ & beta & SE & $p$ & & & & beta & $\mathrm{SE}$ & $p$ & beta & SE & $p$ & beta & SE & $p$ \\
\hline systolic blood pressure (mmHg) & 0.13 & 0.84 & 0.87 & 1.77 & 0.85 & 0.04 & & & & 0.40 & 0.83 & 0.63 & 1.38 & 0.87 & 0.11 & 0.00 & 1.31 & 1.00 \\
\hline diastolic blood pressure $(\mathrm{mmHg})$ & 0.42 & 0.86 & 0.62 & 1.69 & 0.78 & 0.03 & & & & 1.13 & 0.68 & 0.10 & 1.42 & 0.56 & 0.01 & 0.30 & 1.08 & 0.78 \\
\hline HDL (mg/dL) & -1.19 & 0.95 & 0.21 & -1.09 & 0.96 & 0.26 & & & & -1.30 & 0.91 & 0.16 & -0.83 & 0.92 & 0.37 & 0.50 & 1.35 & 0.97 \\
\hline LDL (mg/dL) & -4.09 & 2.23 & 0.07 & -3.93 & 1.86 & 0.03 & & & & -0.68 & 2.10 & 0.75 & -1.12 & 1.86 & 0.55 & 5.19 & 3.00 & 0.08 \\
\hline total cholesterol $(\mathrm{mg} / \mathrm{dL})$ & -5.11 & 2.36 & 0.03 & -5.29 & 2.14 & 0.01 & & & & -1.10 & 2.33 & 0.64 & -1.77 & 2.17 & 0.42 & 6.33 & 3.24 & 0.05 \\
\hline triglycerides $(\mathrm{mg} / \mathrm{dL})$ & 1.55 & 3.20 & 0.63 & 0.11 & 3.72 & 0.98 & & & & 5.07 & 2.86 & 0.08 & 2.63 & 3.11 & 0.40 & 3.87 & 4.91 & 0.16 \\
\hline \multirow[t]{3}{*}{ glucose (mg/dL) } & -0.75 & 1.96 & 0.70 & -0.78 & 1.95 & 0.69 & & & & 1.70 & 1.65 & 0.30 & 1.36 & 1.44 & 0.34 & 5.30 & 3.63 & 0.14 \\
\hline & \multicolumn{9}{|c|}{ gestational weight gain $(n=219)$} & \multicolumn{9}{|c|}{ waist circumference $(n=101)$} \\
\hline & \multicolumn{3}{|c|}{ unadjusted } & \multicolumn{3}{|c|}{ adjusted * } & \multicolumn{3}{|c|}{ adjusted + BMI } & \multicolumn{3}{|c|}{ unadjusted } & \multicolumn{3}{|c|}{ adjusted * } & \multicolumn{3}{|c|}{ adjusted + BMI } \\
\hline & beta & SE & $p$ & beta & SE & $p$ & beta & SE & $p$ & beta & SE & $p$ & beta & SE & $p$ & beta & SE & $p$ \\
\hline systolic blood pressure (mmHg) & -1.11 & 0.83 & 0.18 & 0.63 & 0.86 & 0.46 & 0.82 & 0.85 & 0.34 & -0.94 & 0.93 & 0.31 & -0.25 & 0.91 & 0.78 & -0.76 & 2.57 & 0.77 \\
\hline diastolic blood pressure $(\mathrm{mmHg})$ & -0.94 & 0.77 & 0.23 & 0.16 & 0.71 & 0.82 & 0.11 & 0.67 & 0.87 & 0.34 & 0.86 & 0.69 & 0.20 & 0.79 & 0.80 & -0.20 & 1.95 & 0.92 \\
\hline HDL (mg/dL) & -0.61 & 0.76 & 0.43 & 0.00 & 0.65 & 1.00 & -0.23 & 0.64 & 0.72 & -2.44 & 1.22 & 0.05 & -1.38 & 1.36 & 0.31 & -7.04 & 4.48 & 0.12 \\
\hline LDL (mg/dL) & 0.21 & 2.07 & 0.92 & 0.45 & 2.05 & 0.83 & -0.21 & 2.13 & 0.92 & -3.67 & 3.26 & 0.26 & -4.39 & 2.35 & 0.06 & 4.75 & 7.59 & 0.53 \\
\hline total cholesterol $(\mathrm{mg} / \mathrm{dL})$ & 1.39 & 2.27 & 0.54 & 0.73 & 2.26 & 0.75 & -0.22 & 2.32 & 0.93 & -6.10 & 3.47 & 0.08 & -7.68 & 2.89 & 0.01 & 0.44 & 7.24 & 0.95 \\
\hline triglycerides $(\mathrm{mg} / \mathrm{dL})$ & 7.28 & 3.10 & 0.02 & 1.48 & 3.06 & 0.63 & 0.68 & 3.16 & 0.83 & 1.02 & 3.67 & 0.78 & -5.32 & 3.79 & 0.16 & 15.51 & 11.61 & 0.18 \\
\hline glucose $(\mathrm{mg} / \mathrm{dL})$ & -1.06 & 1.42 & 0.45 & -1.20 & 1.20 & 0.31 & -1.10 & 1.21 & 0.36 & 1.37 & 2.18 & 0.53 & 1.20 & 1.67 & 0.47 & 2.52 & 7.57 & 0.74 \\
\hline
\end{tabular}

* adjusted for mother's age, daughter's age, daughter's BMI, and race. GEE, generalized estimating equation. BMI, body mass index. HDL, high-density lipoprotein. LDL, low-density lipoprotein. 
Table 4. Grandmaternal cardiovascular risk as a predictor of birth outcomes in grandchildren of female Bogalusa Heart Study participants.

\begin{tabular}{|c|c|c|c|c|c|c|c|c|c|c|c|c|}
\hline \multirow[t]{3}{*}{ Risk Factor } & \multicolumn{6}{|c|}{ Birthweight $(n=110)$} & \multicolumn{6}{|c|}{ Gestational Age $(n=110)$} \\
\hline & \multicolumn{3}{|c|}{ unadjusted } & \multicolumn{3}{|c|}{ adjusted } & \multicolumn{3}{|c|}{ unadjusted } & \multicolumn{3}{|c|}{ adjusted } \\
\hline & beta & SE & $p$ & beta & SE & $p$ & beta & SE & $p$ & beta & SE & $p$ \\
\hline BMI & -70 & 79 & 0.38 & -12 & 86 & 0.89 & -0.41 & 0.28 & 0.14 & -0.49 & 0.30 & 0.11 \\
\hline subscapular skinfold & -67 & 76 & 0.38 & 1 & 73 & 0.99 & -0.35 & 0.28 & 0.21 & -0.33 & 0.23 & 0.15 \\
\hline weight gain during pregnancy with mother & 20 & 59 & 0.74 & -4 & 59 & 0.94 & -0.15 & 0.23 & 0.51 & -0.16 & -0.12 & 0.23 \\
\hline systolic blood pressure $(\mathrm{mmHg})$ & -34 & 48 & 0.48 & 2 & 52 & 0.97 & 0.27 & 0.20 & 0.18 & 0.34 & 0.22 & 0.13 \\
\hline diastolic blood pressure $(\mathrm{mmHg})$ & 9 & 44 & 0.84 & 51 & 42 & 0.23 & 0.06 & 0.13 & 0.67 & 0.17 & 0.15 & 0.26 \\
\hline $\mathrm{HDL}(\mathrm{mg} / \mathrm{dL})$ & -56 & 46 & 0.23 & -65 & 47 & 0.17 & -0.30 & 0.17 & 0.08 & -0.37 & 0.18 & 0.04 \\
\hline $\mathrm{LDL}(\mathrm{mg} / \mathrm{dL})$ & -12 & 48 & 0.81 & 15 & 45 & 0.75 & -0.01 & 0.16 & 0.93 & 0.07 & 0.14 & 0.62 \\
\hline total cholesterol $(\mathrm{mg} / \mathrm{dL})$ & -35 & 39 & 0.38 & -55 & 41 & 0.17 & -0.26 & 0.15 & 0.09 & -0.40 & 0.17 & 0.02 \\
\hline & -66 & 49 & 0.17 & -100 & 52 & 0.06 & -0.11 & 0.21 & 0.61 & -0.15 & 0.26 & 0.56 \\
\hline \multirow[t]{4}{*}{ glucose $(\mathrm{mg} / \mathrm{dL})$} & -15 & 42 & 0.73 & 26 & 46 & 0.57 & -0.02 & 0.16 & 0.91 & 0.03 & 0.18 & 0.86 \\
\hline & \multicolumn{6}{|c|}{ low birthweight in any pregnancy ( $n=121,17$ cases) } & \multicolumn{6}{|c|}{ preterm birth $(n=121,13$ cases $)$} \\
\hline & \multicolumn{3}{|c|}{ unadjusted } & \multicolumn{3}{|c|}{ adjusted } & \multicolumn{3}{|c|}{ unadjusted } & \multicolumn{3}{|c|}{ adjusted } \\
\hline & $\begin{array}{l}\text { odds } \\
\text { ratio }\end{array}$ & \multicolumn{2}{|c|}{$95 \% \mathrm{CI}$} & $\begin{array}{l}\text { odds } \\
\text { ratio }\end{array}$ & \multicolumn{2}{|c|}{$95 \% \mathrm{CI}$} & $\begin{array}{l}\text { odds } \\
\text { ratio }\end{array}$ & \multicolumn{2}{|c|}{$95 \% \mathrm{CI}$} & $\begin{array}{l}\text { odds } \\
\text { ratio }\end{array}$ & \multicolumn{2}{|c|}{$95 \%$ CI } \\
\hline BMI & 1.54 & \multicolumn{2}{|c|}{$0.91,2.58$} & 1.40 & \multicolumn{2}{|c|}{$0.80,2.45$} & 2.66 & \multicolumn{2}{|c|}{$1.41,5.02$} & 2.59 & \multicolumn{2}{|c|}{$1.35,4.95$} \\
\hline subscapular skinfold & 1.33 & \multicolumn{2}{|c|}{$0.72,2.48$} & 1.09 & \multicolumn{2}{|c|}{$0.53,2.25$} & 2.26 & \multicolumn{2}{|c|}{$1.18,4.35$} & 2.07 & \multicolumn{2}{|c|}{$1.13,3.78$} \\
\hline weight gain during pregnancy with mother & 0.78 & \multicolumn{2}{|c|}{$0.44,1.39$} & 0.94 & \multicolumn{2}{|c|}{$0.48,1.81$} & 0.95 & \multicolumn{2}{|c|}{$0.52,1.76$} & 1.01 & \multicolumn{2}{|c|}{$0.52,1.93$} \\
\hline systolic blood pressure (mmHg) & 1.34 & & & 1.14 & & & 0.65 & & & 0.58 & 0.30 & \\
\hline diastolic blood pressure $(\mathrm{mmHg})$ & 1.60 & & & 1.44 & & & 0.97 & & & 0.80 & 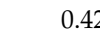 & \\
\hline $\operatorname{HDL}(\mathrm{mg} / \mathrm{dL})$ & 1.10 & & & 1.12 & & & 1.17 & & & 1.18 & 0.72 & \\
\hline $\mathrm{LDL}(\mathrm{mg} / \mathrm{dL})$ & 1.02 & & & 0.90 & & & 0.98 & & & 1.04 & 0.70 & \\
\hline total cholesterol $(\mathrm{mg} / \mathrm{dL})$ & 1.05 & & & 1.13 & & & 1.10 & & & 1.09 & 0.65 & \\
\hline triglycerides $(\mathrm{mg} / \mathrm{dL})$ & 1.07 & & & 1.16 & & & 0.97 & & & 0.88 & 0.48 & \\
\hline glucose (mg/dL) & 1.36 & & & 1.13 & & & 1.30 & & & 1.34 & 0.8 & \\
\hline
\end{tabular}

low-density lipoprotein. 


\section{Discussion}

This study examined possible prenatal and multigenerational effects of cardiometabolic risk factors on offspring cardiovascular health and grand-offspring birth outcomes. In a few cases, we found that maternal pre-pregnancy adiposity predicted daughters' adolescent or adult cardiovascular risk, even controlling for her own BMI. Maternal pre-pregnancy BMI was associated with higher blood pressure, lower LDL, and lower total cholesterol levels in the daughters, and the maternal subscapular skinfold was associated with higher daughters' total cholesterol. In addition, maternal BMI and blood pressure was stronger in black women, while the association between maternal BMI and HDL was stronger for white women. A previous small study comparing offspring of overweight and normal-weight women [6] found a significant difference in blood pressure, which is similar in size to that seen in black women in our study (Some other studies use a different scale of exposure: comparing obese and non-obese participants, or per one-unit change rather than one-SD. For purposes of these comparisons, the effect sizes for these studies were approximated by converting to a 1-SD effect based on their published SDs). They also found large differences in metabolic factors (though not glucose, the only similar factor we measured directly). Another large study found the offspring of obese women to have higher blood pressure compared to those in other BMI categories, but no differences in cholesterol, and small to no differences in triglycerides [7]. This study also found differences in blood pressure, but not as large as we did. A previous analysis of the Jerusalem Perinatal Study found very similar effect sizes as we did for the effect of maternal pre-pregnancy BMI on systolic and diastolic blood pressure, a similar lack of effect on glucose, and larger effect sizes for HDL and LDL [9].

In addition, there were some associations between maternal pre-pregnancy cardiovascular risk and grand-offspring gestational age even though more associations tested were null. Diastolic blood pressure was associated with a higher risk of LBW. Higher cholesterol and LDL are associated with lower gestational age. Higher BMI and skinfold are associated with an increased risk of PTB and triglycerides are associated with lower birthweight. Our previous study of a different sample within BHS found stronger effects for glucose on birthweight and similar effect sizes for lipids [19]. We are not aware of other studies addressing this precise topic.

Effects of maternal and grandmaternal adiposity on offspring health are biologically plausible. Several animal studies have addressed transgenerational relationships among birth outcomes, adiposity, and glucose/insulin metabolism. In Wistar rats, low protein diet was associated with low birthweight and then increased glycemia in generation 2 and higher birthweight in generation 3 [26]. Trunk diameter at birth and back and intramuscular fat were larger in grand-offspring of overfed and underfed swine. Lipid levels were higher from the overfed group [27]. Generation 3 lambs had elevated glucose levels after generation 1 overfeeding. Total fat at birth was higher and thoracic girth lower even though there was no difference in birthweight [28]. In addition, a restricted diet during pregnancy or lactation led to offspring with evidence of insulin resistance in generations 2 and 3 in Wistar rats [29], and uteroplacental insufficiency leading to low birthweight in generation 2 was associated with changes in insulin response in generation 3 Wistar-Kyoto rats [30]. In female Sprague-Dawley rats, a high-fat diet during pregnancy and lactation was associated with increased body weight and glucose intolerance in generation 3 offspring due to changes in $\beta$-cell function and proliferation [31].

BMI is a general indicator of overall adiposity, but, in some cases, waist circumference or skinfold may be a stronger predictor of adverse health [32,33]. For such factors, adjustment for BMI may indicate visceral or subcutaneous fat. Excess abdominal fat is hypothesized to affect health via fat storage and metabolic dysfunction around internal organs and induction of worsened insulin resistance, lipoprotein metabolism, and blood pressure [34]. Overall, we found higher maternal BMI to be associated with higher blood pressure. Contrary to the hypothesis, however, total cholesterol and LDL were lower. For skinfold, adjustment for BMI created a positive association, with higher skinfold predicting higher cholesterol for a given BMI. The reasons for this are difficult to determine, given that abdominal fat is generally more strongly associated with cardiometabolic health than subcutaneous fat $[35,36]$. One previous study did note a stronger association with maternal glucose during pregnancy 
for subcutaneous fat than waist circumference [37], which means it is possible that pregnancy-related adiposity functions differently.

Epigenetic research has provided a possible mechanism by which social factors might get "under the skin" to impact health and engender health disparities at the population level [38]. Epigenetic variation contributes to variation in gene expression and risk for cardiovascular disease [39]. Changes in methylation associated with poor health could occur following social adversity at any point in the life course [40], and can even be transferred to the next generation [41]. This could help explain persistent health disparities observed even in those whose adult life circumstances are not obviously deprived [42]. When we examined racial differences in the associations, we did find some to be stronger in black women and some in white, which suggests that future studies with sufficient power to address this in detail should be conducted. Epigenetic differences associated with pre-pregnancy maternal BMI have been found in offspring, and could indicate a mechanism by which generation 1 effects could be translated to generation 3 [43].

This study was a pilot work, partially to test feasibility of two-generation recruitment, and to provide initial data on effect sizes. As such, many comparisons were underpowered, and control for confounding was limited. This is especially the case for associations where the exposure was measured only in a subgroup (such as waist circumference), or for whom not all women were eligible (birth outcomes were limited to those who had given birth). Future studies should aim for larger sample sizes that will address these limitations and allow for robust control for sociodemographic, environmental, and genetic confounders and clustering within family. That said, our results and effect sizes were generally consistent with previous studies.

An additional limitation is the lack of information on the fathers and grandfathers of the study participants. Future studies should gather information on both parents and grandparents, if possible, to allow for control for lifestyle factors and for testing epigenetic hypotheses (which may arise from either parent, and in some studies, have indicated stronger paternal effects $[13,44])$.

\section{Conclusions}

Future studies should include larger samples, paternal measures, mechanistic indicators, and control for confounding that allows for robust conclusions on this important topic. Our results were similar in effect sizes and outcomes to other multigenerational studies. In summary, we found relationships between some measures of maternal adiposity, daughters' cardiovascular risk factors, and grandchild birth outcomes.

Author Contributions: Conceptualization, E.W.H., J.W.A., and L.A.B. Methodology, E.W.H., J.W.A., and L.A.B. Formal Analysis, E.W.H. Resources, L.A.B. Writing-Original Draft Preparation, E.W.H. Writing-Review \& Editing, J.W.A. Supervision, E.W.H. and L.A.B. Project Administration, E.W.H. and L.A.B. Funding Acquisition, E.W.H. and L.A.B.

Funding: The Bogalusa Heart Study is supported by grants R01HD069587, R01HL016592, R01AG041200, P50HL015103, and R01HD032194. Bogalusa Daughters is supported in part by U54 GM104940 from the National Institute of General Medical Sciences of the National Institutes of Health, which funds the Louisiana Clinical and Translational Science Center. The content is solely the responsibility of the authors and does not necessarily represent the official views of the National Institutes of Health. Additional support provided by the Tulane Bridge Fund and the Bernick Faculty Research Grants.

Conflicts of Interest: The authors declare no conflict of interest.

\section{References}

1. Alexander, G.R.; Kogan, M.D.; Himes, J.H.; Mor, J.M.; Goldenberg, R. Racial differences in birthweight for gestational age and infant mortality in extremely-low-risk US populations. Paediatr. Perinat. Epidemiol. 1999, 13, 205-217. [CrossRef] [PubMed]

2. Collins, J.W., Jr.; David, R.J.; Simon, D.M.; Prachand, N.G. Preterm birth among African American and white women with a lifelong residence in high-income Chicago neighborhoods: An exploratory study. Ethn. Dis. 2007, 17, 113-117. [PubMed] 
3. Hatch, M.; Berkowitz, G.; Janevic, T.; Sloan, R.; Lapinski, R.; James, T.; Barth, W.H., Jr. Race, cardiovascular reactivity, and preterm delivery among active-duty military women. Epidemiology 2006, 17, 178-182. [CrossRef] [PubMed]

4. Whitehead, N.; Helms, K. Racial and ethnic differences in preterm delivery among low-risk women. Ethn. Dis. 2010, 20, 261-266.

5. Barker, D.J.; Eriksson, J.G.; Forsen, T.; Osmond, C. Fetal origins of adult disease: Strength of effects and biological basis. Int. J. Epidemiol. 2002, 31, 1235. [CrossRef] [PubMed]

6. Tan, H.C.; Roberts, J.; Catov, J.; Krishnamurthy, R.; Shypailo, R.; Bacha, F. Mother's pre-pregnancy BMI is an important determinant of adverse cardiometabolic risk in childhood. Pediatr. Diabetes 2015, 16, 419-426. [CrossRef] [PubMed]

7. Gaillard, R.; Steegers, E.A.; Duijts, L.; Felix, J.F.; Hofman, A.; Franco, O.H.; Jaddoe, V.W. Childhood cardiometabolic outcomes of maternal obesity during pregnancy: The Generation R Study. Hypertension 2014, 63, 683-691. [CrossRef]

8. Gaillard, R.; Welten, M.; Oddy, W.H.; Beilin, L.J.; Mori, T.A.; Jaddoe, V.W.; Huang, R.C. Associations of maternal prepregnancy body mass index and gestational weight gain with cardio-metabolic risk factors in adolescent offspring: A prospective cohort study. BJOG 2016, 123, 207-216. [CrossRef]

9. Hochner, H.; Friedlander, Y.; Calderon-Margalit, R.; Meiner, V.; Sagy, Y.; Avgil-Tsadok, M.; Burger, A.; Savitsky, B.; Siscovick, D.S.; Manor, O. Associations of maternal prepregnancy body mass index and gestational weight gain with adult offspring cardiometabolic risk factors: The Jerusalem Perinatal Family Follow-up Study. Circulation 2012, 125, 1381-1389. [CrossRef]

10. Savona-Ventura, C.; Savona-Ventura, S. The inheritance of obesity. Best Pract. Res. Clin. Obstet. Gynaecol. 2015, 29, 300-308. [CrossRef]

11. Davis, M.M.; McGonagle, K.; Schoeni, R.F.; Stafford, F. Grandparental and parental obesity influences on childhood overweight: Implications for primary care practice. J. Am. Board Fam. Med. 2008, 21, 549-554. [CrossRef] [PubMed]

12. Li, J.; Liu, S.M.; Li, S.T.; Feng, R.N.; Na, L.X.; Chu, X.; Wu, X.Y.; Niu, Y.C.; Sun, Z.X.; Han, T.S.; et al. Prenatal exposure to famine and the development of hyperglycemia and type 2 diabetes in adulthood across consecutive generations: A population-based cohort study of families in Suihua, China. Am. J. Clin. Nutr. 2017, 105, 221-227. [CrossRef]

13. Bygren, L.O.; Tinghog, P.; Carstensen, J.; Edvinsson, S.; Kaati, G.; Pembrey, M.E.; Sjostrom, M. Change in paternal grandmothers' early food supply influenced cardiovascular mortality of the female grandchildren. BMC Genet. 2014, 15, 12. [CrossRef] [PubMed]

14. Finkelstein, E.A.; Khavjou, O.A.; Mobley, L.R.; Haney, D.M.; Will, J.C. Racial/ethnic disparities in coronary heart disease risk factors among WISEWOMAN enrollees. J. Womens Health 2004, 13, 503-518. [CrossRef]

15. Kurian, A.K.; Cardarelli, K.M. Racial and ethnic differences in cardiovascular disease risk factors: A systematic review. Ethn. Dis. 2007, 17, 143-152.

16. Arbour, M.W.; Corwin, E.J.; Salsberry, P.J.; Atkins, M. Racial differences in the health of childbearing-aged women. MCN Am. J. Matern. Child Nurs. 2012, 37, 262-268. [CrossRef] [PubMed]

17. Naess, O.; Stoltenberg, C.; Hoff, D.A.; Nystad, W.; Magnus, P.; Tverdal, A.; Davey Smith, G. Cardiovascular mortality in relation to birth weight of children and grandchildren in 500,000 Norwegian families. Eur. Heart J. 2013, 34, 3427-3436. [CrossRef]

18. Agius, R.; Savona-Ventura, C.; Vassallo, J. Transgenerational metabolic determinants of fetal birth weight. Exp. Clin. Endocrinol. Diabetes 2013, 121, 431-435. [CrossRef]

19. Harville, E.W.; Jacobs, M.B.; Qi, L.; Chen, W.; Bazzano, L.A. Multigenerational cardiometabolic risk as a predictor of birth outcomes: The bogalusa heart study. J. Pediatr. 2017, 181, 154-162. [CrossRef]

20. Freedman, D.S.; Dietz, W.H.; Srinivasan, S.R.; Berenson, G.S. The relation of overweight to cardiovascular risk factors among children and adolescents: The bogalusa heart study. Pediatrics 1999, 103, 1175. [CrossRef]

21. Freedman, D.S.; Khan, L.K.; Dietz, W.H.; Srinivasan, S.R.; Berenson, G.S. Relationship of childhood obesity to coronary heart disease risk factors in adulthood: The bogalusa heart study. Pediatrics 2001, 108, 712. [CrossRef] [PubMed]

22. Harville, E.W.; Breckner, D.; Shu, T.; Cooper, M.B.L.A. Establishing a three-generation prospective study: Bogalusa Daughters. 2019; under review. 
23. Ellison, G.T.; de Wet, T.; Matshidze, K.P.; Cooper, P. The reliability and validity of self-reported reproductive history and obstetric morbidity amongst Birth to Ten mothers in Soweto. Curationis 2000, 23, 76-80. [CrossRef] [PubMed]

24. Rice, F.; Lewis, A.; Harold, G.; van den Bree, M.; Boivin, J.; Hay, D.F.; Owen, M.J.; Thapar, A. Agreement between maternal report and antenatal records for a range of pre and peri-natal factors: The influence of maternal and child characteristics. Early Hum. Dev. 2007, 83, 497-504. [CrossRef] [PubMed]

25. Troude, P.; L'Helias, L.F.; Raison-Boulley, A.M.; Castel, C.; Pichon, C.; Bouyer, J.; de La Rochebrochard, E. Perinatal factors reported by mothers: Do they agree with medical records? Eur. J. Epidemiol. 2008, 23, 557-564. [CrossRef] [PubMed]

26. Pinheiro, A.R.; Salvucci, I.D.; Aguila, M.B.; Mandarim-de-Lacerda, C.A. Protein restriction during gestation and/or lactation causes adverse transgenerational effects on biometry and glucose metabolism in F1 and F2 progenies of rats. Clin. Sci. (Lond.) 2008, 114, 381-392. [CrossRef] [PubMed]

27. Gonzalez-Bulnes, A.; Astiz, S.; Ovilo, C.; Lopez-Bote, C.J.; Sanchez-Sanchez, R.; Perez-Solana, M.L.; Torres-Rovira, L.; Ayuso, M.; Gonzalez, J. Early-postnatal changes in adiposity and lipids profile by transgenerational developmental programming in swine with obesity/leptin resistance. J. Endocrinol. 2014, 223, M17-M29. [CrossRef]

28. Shasa, D.R.; Odhiambo, J.F.; Long, N.M.; Tuersunjiang, N.; Nathanielsz, P.W.; Ford, S.P. Multigenerational impact of maternal overnutrition/obesity in the sheep on the neonatal leptin surge in granddaughters. Int. J. Obes. 2015, 39, 695-701. [CrossRef]

29. Zambrano, E.; Martinez-Samayoa, P.M.; Bautista, C.J.; Deas, M.; Guillen, L.; Rodriguez-Gonzalez, G.L.; Guzman, C.; Larrea, F.; Nathanielsz, P.W. Sex differences in transgenerational alterations of growth and metabolism in progeny (F2) of female offspring (F1) of rats fed a low protein diet during pregnancy and lactation. J. Physiol. 2005, 566, 225-236. [CrossRef]

30. Tran, M.; Gallo, L.A.; Jefferies, A.J.; Moritz, K.M.; Wlodek, M.E. Transgenerational metabolic outcomes associated with uteroplacental insufficiency. J. Endocrinol. 2013, 217, 105-118. [CrossRef]

31. Huang, Y.H.; Ye, T.T.; Liu, C.X.; Wang, L.; Chen, Y.W.; Dong, Y. Maternal high-fat diet impairs glucose metabolism, beta-cell function and proliferation in the second generation of offspring rats. Nutr. Metab. 2017, 14. [CrossRef] [PubMed]

32. Jacobs, E.J.; Newton, C.C.; Wang, Y.; Patel, A.V.; McCullough, M.L.; Campbell, P.T.; Thun, M.J.; Gapstur, S.M. Waist circumference and all-cause mortality in a large US cohort. Arch. Intern. Med. 2010, 170, 1293-1301. [CrossRef] [PubMed]

33. Janiszewski, P.M.; Janssen, I.; Ross, R. Does waist circumference predict diabetes and cardiovascular disease beyond commonly evaluated cardiometabolic risk factors? Diabetes Care 2007, 30, 3105-3109. [CrossRef] [PubMed]

34. Klein, S.; Allison, D.B.; Heymsfield, S.B.; Kelley, D.E.; Leibel, R.L.; Nonas, C.; Kahn, R. Waist circumference and cardiometabolic risk: A consensus statement from shaping America's health: Association for Weight Management and Obesity Prevention; NAASO, the Obesity Society; the American Society for Nutrition; and the American Diabetes Association. Diabetes Care 2007, 30, 1647-1652. [CrossRef] [PubMed]

35. Pi-Sunyer, X. Changes in body composition and metabolic disease risk. Eur. J. Clin. Nutr. 2018. [CrossRef] [PubMed]

36. Sam, S. Differential effect of subcutaneous abdominal and visceral adipose tissue on cardiometabolic risk. Horm. Mol. Biol. Clin. Investig. 2018, 33. [CrossRef]

37. Tomedi, L.E.; Simhan, H.N.; Chang, C.C.; McTigue, K.M.; Bodnar, L.M. Gestational weight gain, early pregnancy maternal adiposity distribution, and maternal hyperglycemia. Matern Child Health J. 2014, 18, 1265-1270. [CrossRef]

38. Francis, D.D. Conceptualizing child health disparities: A role for developmental neurogenomics. Pediatrics 2009, 124 (Suppl. 3), S196-S202. [CrossRef]

39. Monte, E.; Vondriska, T.M. Epigenomes: The missing heritability in human cardiovascular disease? Proteom. Clin. Appl. 2014, 8, 480-487. [CrossRef]

40. Kuzawa, C.W.; Sweet, E. Epigenetics and the embodiment of race: Developmental origins of US racial disparities in cardiovascular health. Am. J. Hum. Biol. 2009, 21, 2-15. [CrossRef] 
41. Demetriou, C.A.; van Veldhoven, K.; Relton, C.; Stringhini, S.; Kyriacou, K.; Vineis, P. Biological embedding of early-life exposures and disease risk in humans: A role for DNA methylation. Eur. J. Clin. Investig. 2015, 45, 303-332. [CrossRef] [PubMed]

42. Collins, J.W., Jr.; Rankin, K.M.; David, R.J. African American women's lifetime upward economic mobility and preterm birth: The effect of fetal programming. Am. J. Public Health 2011, 101, 714-719. [CrossRef] [PubMed]

43. Sharp, G.C.; Lawlor, D.A.; Richmond, R.C.; Fraser, A.; Simpkin, A.; Suderman, M.; Shihab, H.A.; Lyttleton, O.; McArdle, W.; Ring, S.M.; et al. Maternal pre-pregnancy BMI and gestational weight gain, offspring DNA methylation and later offspring adiposity: Findings from the Avon Longitudinal Study of Parents and Children. Int. J. Epidemiol. 2015, 44, 1288-1304. [CrossRef] [PubMed]

44. Veenendaal, M.V.E.; Painter, R.C.; de Rooij, S.R.; Bossuyt, P.M.M.; van der Post, J.A.M.; Gluckman, P.D.; Hanson, M.A.; Roseboom, T.J. Transgenerational effects of prenatal exposure to the 1944-45 Dutch famine. BJOG 2013, 120, 548-554. [CrossRef] [PubMed]

(C) 2018 by the authors. Licensee MDPI, Basel, Switzerland. This article is an open access article distributed under the terms and conditions of the Creative Commons Attribution (CC BY) license (http://creativecommons.org/licenses/by/4.0/). 